\title{
EL DESARROLLO \\ DE LA CONSTITUCIÓN SOCIAL
}

\author{
GERARDO RUIZ-RICO RUIZ
}


1. DÉFICITS Y POTENCIALIDADES NORMATIVAS DE LOS DERECHOS SOCIALES EN LA CONSTITUCIÓN ESPAÑOLA DE 1978. 2. UNA APROXIMACIÓN A LA VACILANTE JURISPRUDENCIA CONSTITUCIONAL SOBRE LOS DERECHOS SOCIALES Y SU RELATIVA CAPACIDAD NORMATIVA. 3. LA ESTABILIDAD PRESUPUESTARIA Y LA CRISIS ECONÓMICA: NUEVOS CÁNONES DE CONSTITUCIONALIDAD DE LOS DERECHOS SOCIALES EN LA LEGISLACIÓN Y LA JURISPRUDENCIA CONSTITUCIONAL. 4. EL DESARROLLO TERRITORIAL DE LA CONSTITUCIÓN SOCIAL. 5. CONCLUSIONES: EL ESTADO SOCIAL EN UNA FUTURA CONSTITUTIONE FERENDA. 


\title{
EL DESARROLLO DE LA CONSTITUCIÓN SOCIAL
}

\author{
GERARDO RUIZ-RICO RUIZ* \\ Catedrático de Derecho Constitucional \\ Universidad de Jaén
}

\section{DÉFICITS Y POTENCIALIDADES NORMATIVAS DE LOS DERECHOS SOCIALES EN LA CONSTITUCIÓN ESPAÑOLA \\ DE 1978}

La Constitución española de 1978 (CE) se enmarca en un período donde los textos fundamentales amplían sus respectivos bloques dogmáticos para integrar todo un nuevo catálogo de derechos y objetivos de perfil netamente social. Se pretendía dar respuesta de este modo a una serie de demandas sociales que estaban emergiendo en contextos históricos, políticos y económicos muy distintos a los que habían configurado el constitucionalismo de la postguerra.

Las Constituciones europeas de la década de los setenta fueron promulgadas bajo unas condiciones políticas similares (transiciones democráticas desde regímenes dictatoriales) e incorporan, junto a una versión actualizada de las tradicionales categorías de derechos civiles y políticos de etapas anteriores, una inédita generación de cláusulas sociales y económicas ${ }^{1}$. Esa evolución se puede constatar perfectamente si se comparan además de los enunciados, las fórmulas y técnicas de positivación que se emplean en uno y otro caso. Así, frente a la generalidad y la limitación de contenidos que caracterizan los textos fundamen-

* Departamento de Derecho Público. Universidad de Jaén. Campus Las Lagunillas s/n. Edificio Ciencias Sociales y Jurídicas (D3). 23071 Jaén. Email: gruiz@ujaen.es

1 Pizzorusso cuestiona no obstante cualquier tesis «generacional», por considerar que no tiene una clara fundamentación jurídica, y adopta por el contrario una posición favorable a la «indivisibilidad» de los diferentes derechos constitucionales. Vid. A. Pizzorusso, «Las "generaciones" de derechos», en Anuario de Derechos Humanos, vol. 3, 2002, pp. 493 y ss. 
tales precedentes (Ley Fundamental de Bonn de 1949, Constitución italiana de 1947 y Constitución francesa de 1958), las Constituciones «mediterráneas» de los setenta van a confeccionar un auténtico programa social, en donde aparecen nuevos derechos, hasta entonces desconocidos o solo indirectamente apuntados, junto a directrices más concretas en su finalidad, y objetivos a través de los cuales se aspira a consolidar un modelo social y económico más igualitario.

Sin duda, la CE responde a este nuevo modelo de Constitucionalismo social o dirigente (Gomez Canotilho) ${ }^{2}$, aunque con unas particularidades que en parte desvirtúan su potencial transformador de la realidad sobre la que se aplica. En efecto, la impresión que se obtiene de una primera lectura de su articulado no es otra que la extraña paradoja que existe entre, de un lado, la considerable extensión del catálogo de derechos que condensan la noción de Estado social, y de otro la escasa virtualidad normativa que le proporcionan los instrumentos de garantía diseñados en la norma constitucional. Esta anticipada conclusión se puede ya verificar con el cambio de nomenclatura que se produce durante el proceso constituyente; de la originaria denominación que recibieron en el primer borrador de futura Constitución (derechos sociales y económicos) se pasó a un título definitivo (principios rectores de la política social y económica), que intentaba evitar cualquier presunción o derivación indirecta en adelante de potenciales derechos subjetivos.

En todo caso, la experiencia posterior ha demostrado en buena medida — si bien todavía con déficits notables - cómo esa desvalorización que se infiere del diseño constitucional de los derechos sociales no se corresponde al final con su importancia poliédrica real, que se proyecta de forma transversal en el ámbito político, institucional y normativo. A pesar por tanto de esa velada operación, en el momento fundacional, con la que se pretende desactivar la potencial justiciabilidad de los derechos que componen la Constitución social, su aparente debilidad constitucional no ha impedido finalmente que lleguen a mutar en verdaderos factores de observancia obligatoria en los procesos decisionales y la interpretación jurídica ${ }^{3}$. Así pues, probablemente la medida exacta de su eficacia normativa no se va a reconocer tanto en los dispositivos o las fórmulas de tutela dispensados por la CE, cuanto preferentemente en el desarrollo que obtienen en

${ }^{2}$ Vid. J. J. Gómez Canotilho, « ¿Revisar la/o romper con la constitución dirigente? defensa de un constitucionalismo moralmente reflexivo», en Revista Española de Derecho Constitucional, núm. 43, 1995, pp. 9 y ss. Citamos también aquí sobre este tema, otro de los trabajos del mismo autor, que ha sido referente doctrinal imprescindible, «Tomemos en serio los derechos económicos, sociales y culturales», en Revista del Centro de Estudios Constitucionales, núm. 1, 1988, pp. 239 y ss.

${ }^{3}$ En la medida en que sugiere elementos de normatividad implícitos pero ciertamente efectivos, nos parece acertada esa definición propuesta por K. Hesse, en Escritos de Derecho Constitucional, Centro de Estudios Constitucionales, Madrid. 1983. 
el derecho legislativo primero, y definitivamente después, en el plano de su implementación administrativa.

Pero la constatación de un indudable evolucionismo de los principios y derechos sociales ${ }^{4}$ no ha conseguido superar del todo el clásico dilema entre concepciones que se dividen básicamente todavía entre el retoricismo programático y la defensa de una tendencial fundamentalidad ${ }^{5}$; ambas opciones doctrinales se apoyan en argumentos con una sólida base constitucional. Porque no cabe duda de que estamos en presencia de derechos que han sido enunciados por lo general con un elevado grado de imprecisión tanto en lo relativo a su significado constitucional, como sobre el tipo de consecuencias — en forma de obligaciones y mandatos exigibles a los poderes públicos - que conlleva su recepción en la norma fundamental. Por otro lado, tampoco su potencialidad prescriptiva se puede extraer de manera automática del hecho de que una parte de estos derechos hayan sido consagrados en la CE como teóricos —o prefigurados— «derechos subjetivos» (la salud, medio ambiente, vivienda, pensiones actualizadas). El bloque constitucional donde han sido enunciados (Capítulo tercero del Título Primero) tampoco permite dar cobertura, automáticamente al menos, a una pretensión individualizada como hipotéticos derechos de crédito a obtener una intervención prestacional del Estado ${ }^{6}$.

La difusividad como nota predominante de su naturaleza jurídica no solo se predica del objeto o contenido de los derechos sociales, sino igualmente del modelo de titularidad con que se delimitan sus potenciales beneficiarios. En

4 Vid. A. Porras Nadales, «Derecho Constitucional y evolucionismo jurídico», en Revista de Estudios Políticos, núm. 87, 1995, pp. 107 y ss. Asimismo, sobre la evolución de este modelo de Estado en el contexto de las transformaciones y crisis del capitalismo, vid. C. DE CABO, La crisis del estado social, PPU, Barcelona, 1986; y A. PorRas, Introducción a una teoría del Estado postsocial, PPU, Barcelona, 1988.

5 Nos adscribimos pues a la segunda tesis, que han defendido, entre otros, PÉrEz LuÑo y Solozábal. Vid. A. PÉrez Luño. «Los derechos fundamentales», Madrid, 1984, pp. 54 y ss.; vid. J. J. Solozábal, en «Una revisión de la teoría de los derechos fundamentales», Revista Vasca de Administración Pública, núm. 58 (II), 2000.

6 Esos derechos comienzan a garantizarse también a partir de lo que — denominaríamos«prestaciones regulativas». Como paradigma legislativo de esta otra dimensión prestacional-regulativa, se puede aportar la contenida en la Ley reguladora del derecho a la vivienda en Andalucía (Ley 1/2010), donde se califica además como «garantía jurisdiccional», el derecho a «reclamar ante la correspondiente Administración municipal el cumplimiento del deber de aprobar el Plan Municipal de Vivienda y Suelo y promover activamente la ejecución de la programación prevista en el mismo» (art. 24). Analizado en G. RuIz-Rico «La vivienda como derecho social y material competencial en los nuevos Estatutos de Autonomía», en Dret a l'babitatge i servei públic d'allotjament català?. Junto a Juli Ponce, Patricia E. Salkin y Domènec Sibina. Institut d'Estudis Autonomics, Generalitat de Catalunya, Barcelona, pp. 45-82.

N. ${ }^{\circ} 100$, septiembre-diciembre 2017, págs 799-829 
efecto, se trata unas veces de derechos que enuncian bienes jurídicos del conjunto de la sociedad (medio ambiente, cultura, salud), y otras de derechos que se reconocen a colectivos o minorías indeterminadas en términos cuantitativos, pero identificables a partir de unas condiciones sociales y económicas compartidas que generan situaciones de efectiva desigualdad, e inclusive a veces de potencial vulnerabilidad (minusválidos, emigrantes, tercera edad, juventud, consumidores) ${ }^{7}$. En todo caso, resulta evidente que su definitiva titularidad solo puede delimitarse por el legislador, el cual disfruta igualmente aquí de una amplia competencia para delimitar el ámbito subjetivo de sus potenciales beneficiarios (trabajadores, consumidores y usuarios, jóvenes e infancia, tercera edad, discapacitados, o minorías en proceso de exclusión social).

La «ductilidad» se proyecta asimismo como nota predominante sobre el contenido material de los derechos sociales. En primer lugar, porque se configuran en torno a conceptos de difícil concreción jurídica, excesivamente genéricos y «dinámicos» (salud, medio ambiente). Esa indeterminación se incrementa probablemente con el uso de adjetivaciones equívocas (vivienda «digna, pensiones «periódicas»), que intentan precisar los mandamientos constitucionales, si bien finalmente acaban legitimando equívocos en su interpretación o permiten implícitamente una «graduación» en su cumplimiento. En esta última línea se posicionaría la propuesta teórica que define a los derechos sociales como mandatos de optimización (Alexy), esto es, disposiciones con un elevado nivel de indeterminación objetiva que otorgan amplios márgenes de discrecionalidad en su interpretación normativa y soportan bajos niveles de tutela jurisdiccional ${ }^{8}$. En definitiva estamos en presencia de derechos diseñados constitucionalmente con una naturaleza jurídica «defectuosa»: ambiguo contenido, imprecisión del sujeto responsable, ausencia de sanciones en caso de incumplimiento, fragilidad o inexistencia como derechos de crédito, falta de determinación en cuanto a metodología de implementación y resultados obligatorios.

7 En cuanto propuesta metodológica que comienza a consolidarse en el análisis constitucional de los derechos sociales, se puede utilizar la variable de la — denominada— «vulnerabilidad», como factor que, desde una dimensión sociológica, resulta útil para explicar tanto la ampliación del significado jurídico —y por añadidura administrativo-prestacional— de los ya clásicos derechos sociales de tercera generación, como la generación de un «subcatálogo» de nuevos derechos que comienzan a tener un relieve autónomo en las cartas de derechos constitucionales y legislativos. Sobre el particular nos parece necesaria la consulta de Vid. M. A. Alegre MarTínez, «Protección constitucional a las personas vulnerables y nuevos derechos», en Revista de Derecho Político, núm. 80, 2011, p. 62. y G. RuIZ-RICO, Fundamentos constitucionales de la vulnerabilidad como factor de legitimación en el reconocimiento de derechos, en http://dv.ujaen.es/goto_docencia_fold_735413.html

8 Vid. R. Alexy, Teoría de los Derechos Fundamentales. Madrid, CEPC, 1993. 
No cabe duda de que los derechos que derivan de la noción social de Estado responden fielmente a la categoría de «derechos de configuración legal». Pero esto no debería ser un argumento insuperable para reconocer en aquéllos algo más que puros «indicadores constitucionales» sin valor jurídico alguno. La mejor prueba de lo contrario se apoyaría - insistimos - en el imponente desarrollo normativo y administrativo que han experimentado desde la promulgación de la CE. Por otra parte, siempre queda intacta y susceptible por tanto de ser activada la utilización de los mecanismos genéricos de control de constitucionalidad (recurso y cuestión de inconstitucionalidad) y, en consecuencia, la fiscalización en potencia de aquellas versiones legislativas diametralmente contrarias o antagónicas con las directrices impuestas por la Constitución. En todo caso, la auténtica condición «normativa» de los derechos y principios sociales no se va a medir tanto por su eventual aplicabilidad, directa o inmediata, en alguno de los órdenes jurisdiccionales (constitucional u ordinario) cuanto, de forma más real y efectiva, por su capacidad para obligar o sujetar a los poderes públicos a los mandatos y fines sociales que se establecen en la Constitución. Desde esta perspectiva se podría superar parte de las incertidumbres que afectan a la naturaleza de las cláusulas sociales constitucionalizadas, centradas sobre todo en el dilema que se plantea entre su eventual justiciabilidad (aplicabilidad directa o inmediatez) y la capacidad (inmediata o potencial) que tienen para imputar prescripciones de obligado cumplimiento. El diagnóstico debería focalizarse preferentemente en determinar la influencia que ejercen estos derechos — sin duda devaluados constitucionalmente- en los procesos decisionales que se adoptan en la arena política de los poderes públicos encargados de su realización. En este otro ámbito se puede medir, con mayor exactitud y realismo, su eficacia real en cuanto mandatos constitucionales que imponen una actuación positiva y «correctamente direccionada» hacia determinados objetivos de política social.

La formulación mayoritariamente principial o programática se exporta de manera significativa a los dispositivos constitucionales de tutela jurisdiccional. La CE «discrimina» en este ámbito sus posibilidades de defensa y control respecto de aquellos derechos a los que aquélla atribuye explícitamente la condición de «fundamentales» ${ }^{9}$. Resulta contradictorio sin duda cómo la «generosa» positivación que llevó a cabo el constituyente de los derechos que derivan del

9 Sin embargo, compartimos en este punto la posición doctrinal que mantiene Pisarello, para el que la exclusión de la condición de «fundamentales» en los derechos sociales se debe con frecuencia a prejuicios extrajurídicos; o bien a la ubicación recibida en el texto constitucional, dentro de un capítulo del título primero del que se deduce solo su naturaleza como «derechos imperfectos». Vid. G. Pissarello, en «Los derechos sociales como derechos exigibles. Potencialidades y limites», Albacete, 2009. 
concepto de Estado social, no se completó después con los adecuados medios de protección que permitieran asegurar una básica o mínima virtualidad normativa. Los datos que suministra el precepto (art. 53) encargado de establecer el sistema general de garantías son suficientemente evidentes. Privados de los mecanismos de tutela que disfrutan los demás derechos constitucionales del Título Primero (contenido esencial, reserva de ley, carácter vinculante), en principio carecen por completo de una mínima aplicabilidad directa. Por otro lado, al haber sido excluidos del ámbito objetivo tanto del amparo judicial (recurso preferente y sumario) como del amparo constitucional, queda bloqueada su eventual exigibilidad jurisdiccional. Por último, el carácter presuntamente «programático» adquiere carta de naturaleza cuando se les otorga un simple valor «informativo» de la legislación, la práctica judicial y la actuación en general de los poderes públicos ${ }^{10}$. En suma, se ponen serios obstáculos para predicar de los derechos sociales una condición auténticamente constitucional, con la que sea viable su utilización como cánones normativos superiores del ordenamiento y por tanto conseguir la invalidación de aquellos desarrollos normativos incompatibles u opuestos a la orientación marcada por la $\mathrm{CE}^{11}$. Un examen de la praxis de los considerados legalmente como sus «garantes naturales» (órganos judiciales) permitiría reconocer sin dificultad la amplia — casi ilimitada_ discrecionalidad regulativa con que ha contado en todo momento el legislador y las Administraciones sociales; y por lo mismo también, la imposibilidad para ser reclamados en el plano jurisdiccional, más allá de su utilización como meros «criterios» o «reglas de interpretación» del ordenamiento jurídico.

El argumento nuclear en el que cabría apoyar una posición jurídica y no meramente programática de los derechos y principios sociales tiene que sustentarse en el mismo principio de constitucionalidad que deriva del art. 9.1, el cual no admite excepción ni tampoco modulaciones a la baja de quienes tienen la obligación de aplicarlo ${ }^{12}$. Se trata por tanto de una regla que garantizaría su

10 Para Rubio Llorente, esa "fuerza informativa es, simplemente, un modo expresivo, aunque torpe, de apuntar la existencia en la Constitución de otras clases de normas materiales, no orgánicas ni atributivas de competencia, que tienen una estructura distinta a la que establece el repertorio de los derechos fundamentales propios, y cuyas consecuencias jurídicas son, por tanto, muy otras». Vid. F. RuBIO LLORENTE, «La forma del poder», CEPC, Madrid, 1997, pp. 52 y ss.

11 Como selección representativa del desacuerdo doctrinal que existe aún en torno a la eficacia - programático-semántica o pro-normativa- de los derechos y principios del Estado social, se puede citar la monografía colectiva, donde se recopilan ponencias y comunicaciones del IX Congreso de la Asociación de Constitucionalistas de España, «Derechos sociales y Principios Rectores», Tirant lo Blanch, Valencia, 2012.

12 Como ha afirmado Cascajo CAstro - autor de referencia en esta materia - "no parece de recibo que el principio de vinculación a la Constitución opere de forma distinta según se trate de los derechos 
condición normativa y, por consiguiente también, la potencial accionabilidad — jurisdiccional — frente a desarrollos infraconstitucionales abiertamente contradictorios. De igual modo, esa «calidad jurídica mínima» no impediría su incorporación a los procesos decisionales que se producen en los circuitos institucionales político-administrativos, actuando como verdaderas directrices vinculantes de la acción pública — si bien con una normatividad ciertamente mitigada - que hacen posible su utilización como parámetros de medición de la validez de normas y actos del conjunto de poderes públicos.

Pese a la expresividad constitucional sobre los fines y mandamientos que contienen las cláusulas sociales (defensa del medio ambiente, seguridad social, salud, vivienda, etc.), se localizan muy pocas referencias sobre la metodología a través de la cual se tienen que implementar por el poder políticoadministrativo. Sólo en algunos principios y derechos se rompe con esta regla general: «procedimientos eficaces» en la defensa de los intereses de consumidores y usuarios, «sanciones» penales y administrativas para prevenir atentados contra el medio ambiente, o «pensiones adecuadas y periódicamente actualizadas» como fórmula para asegurar la calidad de vida mínima de los ciudadanos en la tercera edad. Esta relación tan limitada de instrumentos al servicio del cumplimiento y ejercicio de los derechos sociales tampoco contribuye positivamente a asegurar las posibilidades de un control jurisdiccional efectivo.

Por otro lado, el modelo de titularidad — colectiva/difusa o general del conjunto de la sociedad - de los derechos propios del Estado social explicaría en buena medida la configuración de una dimensión procesual que viene a amplificar el significado constitucional de los derechos sociales. Como status activae civitatis (Jellinek), se van a diseñar de este modo en el articulado de la norma fundamental una serie de dispositivos o «escenarios institucionales», a través de los cuales se puede impulsar el cumplimiento de los objetivos y fines sociales constitucionalizados. En este punto la CE ha dado cobertura parcial - y en consecuencia, deficitaria- a fórmulas de «participación social» en aquellos procesos decisionales orientados a la satisfacción de las demandas de amplios colectivos o genéricos de la ciudadanía ${ }^{13}$.

y libertades reconocidos en el capitulo II del título I, o bien de los Principios Rectores del capítulo III, porque la fuerza normativa de la Constitución (art. 9.1, CE) se proclama respecto de toda ella y no solo en relación con algunas de sus partes o contenidos». Vid. J. L. CasCajo CaSTro, «Derechos sociales», en Derechos sociales y Principios Rectores, Tirant lo Blanch, Valencia, 2012, p. 25.

${ }_{13}$ Sobre esta concepción participativa — no estática ni meramente «intervencionista»— del Estado social, vid. J. Rodríguez ArANA, «La participación en el Estado social y democrático de derecho», en Revista de Derecho y Ciencias Sociales. Bogotá, núm. 7, Año 2014. También es imprescindible examinar en este punto la propuesta de interpretación «integral» de la fórmula del 
Dentro de este otro marco de referencia resulta destacable, en primer lugar, la cláusula constitucional que, con una proyección transversal, mandata a los poderes públicos la promoción de sistemas de participación de los ciudadanos en «la vida política, económica, social, cultural y social» (art. 9.2, CE). Más específicamente relacionada con el concepto de Estado social, el artículo 129.1 de la CE prevé la participación «de los interesados en la Seguridad Social y en la actividad de los organismos públicos cuya función afecte directamente a la calidad de la vida o al bienestar general». Se traza aquí una directriz constitucional que legitima la articulación de aparatos institucionales de intervención de la sociedad —en paralelo y no incompatibles con los mecanismos propios de una democracia representativa- dentro de las Administraciones sociales (Estado y Comunidades Autónomas), con objeto de proporcionar un canal de participación en ellos a aquellos sectores sociales beneficiarios de los derechos y prestaciones sociales.

Por último, y aunque referida solo a determinados derechos, la norma fundamental apunta también una orientación que ha sido después desarrollada legislativamente en la mayoría de los derechos y principios rectores sociales. Las específicas previsiones «procedimentales» quedaron explícitamente reseñadas a lo largo del Título Primero: derecho de participación en la programación de la enseñanza y control en la gestión de los centros educativos (art. 27.5 y 7), derecho de audiencia a las organizaciones de consumidores y usuarios en las cuestiones que puedan afectar a aquéllos (art. 51 2), o participación de la juventud en el desarrollo político, social económico y cultural (art. 48). El legislador, tanto el estatal como el autonómico, ha proporcionado un despliegue organizativo o institucional a esta vertiente «democrática» del Estado social, especialmente en algunos derechos donde resultaba imprescindible la búsqueda de consensos sociales ${ }^{14}$.

artículo 1.1 de la CE (Estado social y democrático de derecho) planteada en su momento GARRORENa Morales en una obra imprescindible, El Estado español como Estado social y democrático de derecho», Tecnos, 1992, pp. 199 y ss.

${ }^{14}$ Con seguridad el derecho al medio ambiente ha recibido el despliegue institucional más completo de esta dimensión procesual, a través de fórmulas y mecanismos que garantizan la intervención de la ciudadanía en general o a través de representantes intereses sectoriales en las diferentes esferas orgánicas de las Administraciones competentes. Sobre una base de origen convencional y europeo - Convenio Aahrus (2004) y Directivas 4 y 35 del 2003 del Parlamento y el Consejo- se aprobó la Ley 27/2006, de 18 de julio, por la que se regulan los derechos de acceso a la información, de participación pública y de acceso a la justicia en materia de medio ambiente. La norma sintetizaba en tres vías principales los modelos de participación que estaban ya presentes en buena parte de la legislación ambiental estatal y autonómica: el acceso a la información ambiental, la participación en la toma de decisiones de las Administración pública y el acceso a la justicia. Hemos dedicado algunos estudios al análisis de las fórmulas de colaboración ciudadana en el 
Sin embargo, estos métodos de colaboración de la ciudadanía, o de sectores de ésta involucrados en objetivos sociales, no han superado hasta el momento una intensidad y eficacia restringidas, al quedar circunscritas funcionalmente en un plano meramente «informativo» o «consultivo», en el marco de determinados procedimientos o circuitos administrativos y, en ocasiones también, legislativos o parlamentarios. En todo caso, no se puede menospreciar la trascendencia positiva para la tutela judicial de los derechos sociales de construcciones jurisprudenciales, más tarde exportadas a un plano legislativo, gracias a las cuales se ha dado cobertura a nuevo concepto de legitimación activa en los procedimientos administrativos y jurisdiccionales. Emblemático en este sentido ha sido la adopción del denominado interés legítimo como principio «aperturista» que ha facilitado la participación social en los procesos decisionales de las Administraciones sociales; además de favorecer una ampliación subjetiva del concepto de «legitimación procesal» en aquellas vías jurisdiccionales donde se sustancian conflictos donde están involucrados derechos de minorías y bienes jurídicos constitucionales de interés general ${ }^{15}$.

Por otro lado, y desde una perspectiva sustantiva, la extracción de un «contenido» si no esencial, por lo menos «mínimo» de los principios sociales, exigiría un método de interpretación que podríamos calificar de «recreativo» o «aditivo» con el que sería viable garantizar una dotación normativa básica a esos mandatos constitucionales y, en consecuencia también, un potencial control de constitucionalidad por parte desde las diferentes instancias jurisdiccionales — TC, órganos judiciales — de acuerdo con sus respectivas competencias en materia de la tutela de derechos.

No obstante, la principal dificultad para adoptar una posición normativa en torno a los derechos constitucionales de naturaleza social sigue centrada en la impotencia que manifiestan la mayor parte de los derechos sociales frente las leyes regresivas del status quo o estándar de protección alcanzado en un momento histórico indefinido. Para neutralizar esta tesis —o cuanto menos para atenuar sus consecuencias en el plano jurídico- cabe proponer y defender una concepción «evolutiva» que dé prioridad a las interpretaciones positivas, frente a las

Estado social; vid. G. RuIz-Rico, «Aspectos constitucionales de la participación en el ámbito institucional del estado social», en Los derechos fundamentales y las libertades públicas». Ministerio de Justicia. Madrid. 1993. Pp. 1471 a 1503; asimismo en «La participación ciudadana en la protección del medio ambiente: especial referencia a la Administración forestal», en Estudios de Derecho Ambiental (I), J. M. Ruiz-Rico, G. Ruiz-Rico y N. Pérez Sola, Coords., Tirant lo Blanch, 2007, pp. 237-252.

${ }^{15}$ Véase como más representativa y de alcance general en este sentido, la regla contenida en el artículo 19.1 de la Ley de la Jurisdicción Contencioso Administrativa (Ley 29/1998). 
restrictivas, de los principios y derechos del Estado social. Pero su aplicación en la praxis legislativa y reglamentaria va a depender del grado de precisión con el que el texto constitucional haya fijado unos estándares prestacionales básicos o mínimos de los derechos sociales, o puedan derivar de éstos unas obligaciones públicas suficientemente definidas, de manera que su incumplimiento permita activar los circuitos de fiscalización jurisdiccional ${ }^{16}$.

No cabe negar, en efecto, la falta de «inmediatez» o la escasez de mecanismos específicos de tutela judicial de los derechos sociales ${ }^{17}$, amplificado por el tipo de enunciados generalmente «promocionales» (los poderes públicos/Estado garantizarán, promoverán, establecerán); o su excesiva desconstitucionalizacion, al estar supeditados de manera indefectible por una posterior legislación que los desarrolle. Pero empieza a consolidarse en un sector doctrinal la tesis de su integración progresiva dentro de la categoría de los «derechos fundamentales» (Solozábal). La propuesta resulta asumible siempre que no se haga depender esa condición de que se hayan creado instrumentos concretos de orden procesal que hagan viable su tutela jurisdiccional; y si se adopta, por el contario, como síntoma o indicador auténtico de su normatividad, el elevado nivel de desarrollo legislativo y administrativo-en menor medida jurisprudencial- alcanzado por los derechos y principios sociales. Desde esta otra perspectiva o enfoque, es evidente que no se puede rechazar de forma apriorística una cierta fundamentalidad de los derechos sociales. Se apoyaría además esta tesis en el hecho de que una parte significativa ya han sido enunciados como derechos subjetivos con el máximo nivel de protección (educación, libertad sindical, huelga). Por otro lado, es necesario «desvalorizar» en su justa medida la trascendencia de la ubicación recibida en el cuadro de la Declaración constitucional de derechos (Título Primero), para reconocer en la mayor parte de aquéllos la existencia de bienes jurídicos de extraordinario impacto social (salud, medio ambiente, etc.), o la garantía directa de otros valores constitucionales (dignidad, calidad de vida), especialmente para minorías socialmente relevantes ( tercera edad, discapacita-

16 Seguiría teniendo vigencia la teoría — sostenida por Baldassarre- de la inevitable diferenciación entre derechos sociales «condicionados» e «incondicionados»; solo en estos últimos la disponibilidad o autonomía de legislador se habría reducido a la hora garantizar la ejecución de los compromisos constitucionales en lo que respecta al «cuándo» y el «cómo». Vid. A. BALDAsSARRE, «Diritti Sociali», en Enciclopedia Jurídica Treccanti, Roma, 1989.

${ }^{17}$ En palabras de RuBio LloRENTE, «los mandatos (sociales) al legislador son fuente de derecho objetivo e imponen obligaciones, pero su eficacia para engendrar derechos subjetivos correlativos de estas obligaciones depende de que el legislador pueda ser forzado a dictar estas leyes sin las cuales se frustra el ejercicio real de derechos contenidos en la Constitución». Vid. F. RuBIo LlORENTE, «La forma del poder», CEPC, Madrid, 1997, pp. 52 y ss. 
dos, dependientes, juventud ). Ciertamente sigue existiendo un matiz, en la medida en que solo de unos pocos (art. 27 y 28), cabe atribuirles la naturaleza de derechos subjetivos reaccionales o impugnatorios; esto es, al no haber sido previsto específicamente un procedimiento jurisdiccional para exigir de la Administración o del Legislador el comportamiento previsto en la norma o la aprobación de una ley de desarrollo, la fuerza vinculante de la mayoría de los principios y derechos sociales se concentraría esencialmente en la prohibición de emanar normas contrarias a las directrices y mandamientos que se señalan por la Constitución.

De todos modos, resulta altamente improbable una fiscalización verdaderamente efectiva tanto de la aplicación deficitaria como de las omisiones legislativa y administrativa que afectan a los derechos encuadrables dentro del concepto de Estado social. El motivo principal es que no se han diseñado constitucionalmente fórmulas ni mecanismos adecuados para solucionar el incumplimiento parcial o la ausencia total de una regulación legislativa, para unos derechos constitucionales cuya principal garantía reside justamente en ese desarrollo normativo, del que depende por lo demás su configuración ya como derechos subjetivos accionables en vía jurisdiccional. Sin embargo, no creemos que sea éste, en la actualidad, el principal problema que enfrenta la materialización de los principios y derechos del Estado social. Como hemos puesto ya de manifiesto, son escasas las posibilidades de un control de constitucionalidad operativo y eficaz frente a la anemia normativa de los poderes públicos ${ }^{18}$. En todo caso, convendría recordar también que frente al problema de la pasividad legislativa o administrativa, el propio TC ha reconocido de forma categórica su falta de idoneidad e incapacidad competencial para sustituir a los órganos encargados de determinar la secuencia de cumplimiento y realización de los fines sociales constitucionalizados.

En definitiva, estamos convencidos de que, tras el extenso despliegue en la esfera legal que han experimentado los derechos sociales durante la vigencia de la CE, es necesario reubicar el debate sobre la eficacia jurídico-constitucional de los derechos del Estado social en el terreno de lo que podríamos denominar como «omisión administrativa»; porque justamente aquí es donde se manifiestan los mayores déficits de satisfacción y cumplimiento. Esta otra perspectiva nos pro-

18 No obstante, en el caso de que exista previamente una exigencia constitucional «concreta», la probabilidad de un control efectivo resulta factible; algo que sucede singularmente en algunos principios rectores del capítulo tercero: Seguridad Social (art. 41), salud (44), medio ambiente (45), actualización de pensiones (art. 51). Se han posicionado también en esta línea, F. FERNÁNDEZ Segado. La dogmática de los derechos humanos, en Lima Ediciones Jurídicas, 1994. p. 334; y J. TAJADURA, «La inconstitucionalidad por omisión», en Los derechos fundamentales en la Unión Europea (J. Corchera, dir.), Dykinson, Madrid, 2002. pp. 443-465. 
porcionaría un enfoque más exacto y verídico sobre su auténtica capacidad para actuar de límites a la autonomía de las decisiones político-administrativas, así como sus potencialidades para activar con ellos un efectivo un control jurisdiccional de constitucionalidad ${ }^{19}$. Esta «difusa» fiscalización a través de los órganos judiciales no tendría por qué limitarse a la técnica habitual de aplicación de la norma fundamental como un mero criterio de interpretación — si bien vinculante formalmente- «conforme a Constitución» ${ }^{20}$. Se podrían además poner en práctica los llamados «tests» de razonabilidad o de proporcionalidad, similares a los que se adoptan en la resolución de supuestos donde están implicados «derechos fundamentales», para asegurar de este modo su condición de verdaderos parámetros de medición constitucional. Con esta premisa metodológica, la garantía de un control efectivo de constitucionalidad no tendría por qué centrarse solo en la definición de unos contenidos concretos, asistenciales o prestacionales que derivarían de los enunciados constitucionales, sino preferentemente en la demarcación de una frontera o línea de divisoria desde la cual sea legítima la invalidación de aquellas medidas y disposiciones regulativas que se alinearan en una dirección diametralmente opuesta a la marcada por el texto fundamental.

\section{UNA APROXIMACIÓN A LA VACILANTE JURISPRUDENCIA CONSTITUCIONAL SOBRE LOS DERECHOS SOCIALES Y SU RELATIVA CAPACIDAD NORMATIVA}

Desde muy temprano, el TC ha trazado una línea divisoria en el Título Primero desde la que ha sido imposible sostener de forma nítida la existencia de un «contenido constitucional» que garantice una mínima de eficacia normativa de los derechos sociales ${ }^{21}$. El principio social, así como los derechos sociales en los

19 Una tesis que sintoniza con la defendida por García FerNáNDEZ, cuando considera —para el caso del derecho a la vivienda - que aquellas regulaciones administrativas (plan de asignación de viviendas) podría ser impugnable judicialmente por vulneración del artículo 47 de la CE, si no garantizan criterios de equidad y razonabilidad para su implementación. Vid. J, GARCía FERNÁNDEZ, «La protección constitucional de la vivienda y su proyección penal: especial referencia a los fenómenos okupa y mobbing inmobiliario», en Derecho y vivienda, Cuadernos de Derecho Judicial, Consejo General del Poder Judicial, Madrid, 2006, p. 2.

${ }^{20}$ Concretamente, hemos podido comprobar cómo la jurisprudencia del Tribunal Supremo otorga de forma reiterada ese valor puramente interpretativo a uno de los principios rectores más emblemáticos (derecho al medio ambiente). Vid. El derecho constitucional al medio ambiente. Dimensión jurisdiccional. Tirant lo Blanch. Valencia. 2000.

${ }^{21}$ Para Pérez Royo, sin embargo, en sus iniciales pronunciamientos el TC se esforzó por concretar y dar significado a la fórmula de Estado social. Primero, al articular la relación que existe entre esta noción del artículo 1.1 con al principio de autonomía (Sentencia 28 de julio 
que se éste se materializa, se van a utilizar esencialmente como elementos de interpretación del ordenamiento, lo que impide que lleguen a disfrutar de la potencia jurídica necesaria para anular aquellas normas que contradigan abiertamente los mandatos sociales constitucionalizados. El efectivo control de constitucionalidad de las leyes que aplican y desarrollan los derechos y principios rectores sociales resulta todavía una hipótesis de difícil verificación en la jurisprudencia constitucional española. El TC ha otorgado como regla general un amplio margen de autonomía al legislador para «optimizar» y graduar su cumplimiento. No es posible entonces localizar en su jurisprudencia «social» pronunciamientos inequívocos sobre el valor que poseen esos mandatos y directrices constitucionales como canon efectivo de legitimidad.

Desde este primer balance negativo sobre la inexperiencia aplicativa de la noción social de Estado (art. 1.1) y sus derivados, cabe preguntarse lógicamente hasta qué punto las cláusulas sociales de la CE tendrían para la jurisprudencia constitucional la suficiente entidad normativa, como para apoyar la eventual declaración de nulidad de una legislación regresiva, restrictiva o claramente opuesta al programa social marcado por la norma fundamental ${ }^{22}$. En la doctrina del TC esa posibilidad sólo se ha podido demostrar ocasionalmente, y en concreto solo cuando se ha planteado la conexión intrínseca con alguno de los derechos «fundamentales» ${ }^{23}$. En este sentido, aunque no se trate de una pauta interpretativa frecuente, sin embargo se pueden localizar en la jurisprudencia constitucional algunas resoluciones que vienen a demostrar cómo la relación con los principios de igualdad formal (art. 14) y sustantiva (art. 9.2) puede llegar a proporcionar indirectamente un cierto grado justiciabilidad constitucional al

de 1981), y, en segundo lugar, a través su conexión con el principio de igualdad real y efectiva del artículo 9.2 de la CE (Sentencia 81/1982). Vid. J. PéRez Royo, «La doctrina del tribunal constitucional sobre el Estado social», en Revista española de derecho constitucional, núm. 10, 1984, pp. 157 y ss.

${ }^{22}$ Si bien es cierto - habría que subrayarlo adecuadamente- que no parece correcto otorgar a la jurisprudencia constitucional un rol decisivo en la materialización de los objetivos y fines sociales constitucionalizados, porque — como señala CASCAjo CASTRO- en este tipo de derechos «es esencial la intervención del legislador para dar actuación a las tareas constitucionales según criterios de gradualidad y disponibilidades financieras». Vid. J. L. CasCajo CASTRO, "La tutela de los derechos sociales», Centro de Estudios Constitucionales, Madrid, 1988, pp. 33-34.

${ }^{23}$ En este sentido, el TC se pronunció ya en su momento sobre la funcionalidad potencialmente garantista de esa relación, al declarar que «no cabe excluir que la relación entre alguno de esos principios y los derechos fundamentales (señaladamente el de igualdad) haga posible su examen de este género (por ejemplo nuestra STC 155/1987), ni sobre todo que el principio rector sea utilizado como criterio para resolver la constitucionalidad de una acción positiva del legislador, cuando ésta se plasma en una norma de notable incidencia sobre la entidad constitucionalmente protegida» (STC 45/1989). 
conjunto de derechos y principios sociales; en especial frente a déficits regulativos o normas que conculcan alguno de los derechos consagrados como «fundamentales» ${ }^{24}$.

Esta combinación entre derechos de distinta naturaleza y niveles de tutela ha tenido eco también en algunas sentencias del Tribunal Europeo de Derechos Humanos TEDH. Sin embargo la importación de esta doctrina convencional a la jurisprudencia constitucional nacional no ha sido del todo pacífica. Así, el TC se va mostrar contrario a la traslación automática de esta doctrina que se abría paso en la jurisprudencia convencional, representada especialmente con el caso López Ostra v. Reino de España. En la Sentencia 119/2001 reconocerá la afectación negativa que puede llegar a tener una de las formas más habituales de agresión medioambiental (contaminación acústica) sobre varios derechos fundamentales: vida, integridad psíquica, intimidad e inviolabilidad del domicilio. Pero en contra de lo que cabría presumir, el Tribunal nunca llegó a aceptar la posible conectividad con el derecho al medio ambiente, evitando así la creación de un precedente sobre el que pudiera apoyarse la potencial extensión de la tutela jurisdiccional reforzada (amparo ordinario y constitucional) a derechos — sociales y económicos - que habían quedado excluidos por expresa prescripción constitucional de esos instrumentos especiales de protección (art. 53.2) ${ }^{25}$.

La jurisprudencia constitucional no ha superado todavía la incertidumbre que quedó reflejada ya en sus iniciales pronunciamientos, a pesar de que existen no obstante algunos indicadores de los que es posible inferir un cierto carácter imperativo en los principios y derechos sociales. De este modo, el TC ha afirma-

${ }^{24}$ Uno de los casos más representativos de esta línea jurisprudencial sería STC 103/1983, en la que se va declarar contrario a los artículos 14 (principio de igualdad, prohibición de discriminación en razón de sexo) y 41 (Seguridad social que garantice asistencia y prestaciones sociales ante situaciones de necesidad) el artículo 160-2. ${ }^{\circ}$ de la Ley General de la Seguridad Social, que impedía a los varones viudos el derecho a cobrar una pensión cuando la esposa falllecida había cotizado previamente a la Seguridad Social. El TC viene a reconocer explícitamente en el derecho contenido en el principio rector «un mínimum constitucionalmente garantizado».

25 No obstante, la Sentencia 119/2001 ofrece un interés especial —a nuestro juicio- no tanto por el pronunciamiento de la mayoría de la Sala, sino por la interpretación que sostiene alguno de sus votos particulares. En concreto, la opinión disidente de uno de sus Magistrados (Jiménez de Parga) estaría apuntando una tesis interpretativa que vincula directamente a estos derechos fundamentales con el principio rector del artículo 45. La aportación más relevante de esta posición se refiere a lo que denomina «contenido ambiental» de los derechos fundamentales, así como «el contenido subjetivo de algunos derechos, igualmente fundamentales, pero no protegibles en vía de amparo (singularmente, el reconocido en el artículo 45 CE)». Desde este enfoque verdaderamente «alternativo», el voto particular considera conveniente "reivindicar el contenido o componente subjetivo del artículo $45-1 .^{\circ}$ $C E »$, además de la relevancia constitucional del «ruido ambiental», no solo cuando ponga en peligro la salud — general_ de los ciudadanos o cuando dañe el ámbito específicamente domiciliario». 
do en positivo su valor normativo, cuando sostiene que, "al margen de su mayor o menor generalidad de contenido, enuncian proposiciones vinculantes en términos que se desprenden inequívocamente de los artículos 9 y 53 de la Constitución» (STC 14/1992); o al declarar que estamos en presencia de cláusulas que tienen «peso y significado propios», y no pueden ser reducidos, por consiguiente, a preceptos programáticos ni a simples elementos interpretativos de las normas legales (STC 146/1992). Sin embargo, lo cierto es que hasta el presente el TC no ha llegado a fundar en estos derechos del Capítulo Tercero una pretensión exigible en términos jurisdiccionales, en forma derecho subjetivo e individualizado a recibir una prestación social o a una acción positiva de los poderes públicos; como tampoco hemos podido descubrir pronunciamientos donde se hayan utilizado, de forma categórica y exclusiva, como parámetros para lograr la nulidad de normas con rango de ley.

Seguimos careciendo, pues, de referentes en la doctrina del TC donde se haya puesto en práctica un verdadero control sustantivo de constitucionalidad sobre de normas y actos que comprometan el ejercicio y satisfacción de los derechos socia$\operatorname{les}^{26}$. Aunque de manera indirecta, sí que sería posible reconocer parte del significado y valor constitucional que pueden llegar a tener, a partir del examen de la amplia jurisprudencia constitucional dictada con motivo de los numerosos conflictos competenciales que han afectado al desarrollo «territorial» del Estado social. De este modo, en el hilo argumental de sentencias cuyo objeto principal se centraría en la interpretación del sistema de atribución de competencias entre Estado y CCAA, se pueden localizar la concepción real que tiene el TC de algunos de los perfiles y contenidos sustantivos de los mandatos sociales constitucionalizados. En esta labor de definición del principio social, mediante su conexión con el principio de autonomía, el concepto de «lo básico» ha significado algo más que un instrumento de delimitación funcional entre esferas político-institucionales que comparten objetivos integrables en la noción social de Estado. El valor «social» de la normativa básica se concentra simultáneamente en la delimitación de un «mínimo» estándar esencial de protección social a nivel estatal; y desde ese común denominador igualitario para el conjunto de los ciudadanos el Tribunal acaba indirectamente asegurando un nivel básico de prescripción en los derechos sociales. En este proceso, a un tiempo de igualación territorial y de tutela de unos mínimos sociales, el Estado central ha contado en todo momento

26 Vid. P. Requejo Rodríguez, «El papel de la crisis económica en la argumentación del tribunal Constitucional. Comentario am la STC 119/2014», en Teoría y Realidad Constitucional, núm. 36, 2015, pp. 417 y ss. 
con una cláusula constitucional de proyección expansiva y eficacia recentralizadoras indudables (el art. 149.1.1) ${ }^{27}$.

\section{LA ESTABILIDAD PRESUPUESTARIA Y LA CRISIS ECONÓMICA: NUEVOS CÁNONES DE CONSTITUCIONALIDAD DE LOS DERECHOS SOCIALES EN LA LEGISLACIÓN Y LA JURISPRUDENCIA CONSTITUCIONAL}

La situación de debilidad normativa que sufren la mayor parte de los derechos sociales se agrava periódicamente en tiempos de crisis. La dependencia presupuestaria no es una característica exclusiva de los derechos de naturaleza social $^{28}$; pero lo cierto es que ese posibilismo se acentúa en los derechos que se configuran con un contenido «prestacional», y se incrementa aún más en ese contexto, haciendo realmente difícil, cuando no imposible en la práctica, el bloqueo de aquellas normas y políticas regresivas de los estándares de protección social.

Se podría afirmar incluso que la última versión de crisis económica ha producido una verdadera mutación constitucional de buena parte de los principios y derechos fundamentales del orden constitucional, y en especial de los relacionados con el concepto de Estado social. El grado de devaluación jurídica que está experimentando este último está conduciendo a lo que se ha denominado como Constituciones dirigentes invertidas, en la cuales cabe anotar un innegable incremento de la dependencia y subordinación de los derechos sociales a las prioridades que rigen un modelo económico en estado de emergencia ${ }^{29}$.

La tendencia involutiva en el desarrollo del Estado social es un fenómeno legislativo que puede constatarse además en la reciente jurisprudencia constitucional, en relación con las normas que se han aprobado recientemente para garantizar el nuevo «megaprincipio» de la estabilidad presupuestaria (art. 135),

${ }^{27}$ La doble funcionalidad del precepto mencionado ya fue puesta de manifiesto por L. LópEZ Guerra, «La doctrina del tribunal Constitucional en relación con el artículo 149.1.1», en La función del artículo 149.1.1 en el sistema de distribución de competencias, Generalidad de Cataluña, 1992, pp. 9-24.

28 Holmes y Sustein se posicionan en contra de la tesis tradicional sobre la «independencia económica» de los derechos civiles y políticos del sistema de financiación pública. Vid. S. HoLmes y C. S. Sustein, "El costo de los derechos. Por qué la libertad depende de los impuestos», Madrid, 2011.

29 Pisarello nos familiariza con esta expresión en «El constitucionalismo social ante la crisis: entre la agonía y la refundación republicano-democrática», en Revista Derecho del Estado n. ${ }^{\circ} 28,2012$, pp. 55-75. 
implantado con la última reforma constitucional del $2011^{30}$. Su efecto más perverso se manifiesta esencialmente en forma de banalización de buena parte de la Declaración de derechos de la CE, al validar la legislación y jurisprudencia donde se han reducido de manera extraordinaria los niveles básicos o esenciales de la mayor parte de los derechos que tienen una configuración prestacional ${ }^{31}$.

El TC se ha posicionado de este modo a favor de una interpretación deconstructiva del concepto de Estado social, ampliando la disponibilidad regulativa del legislador para llevar a cabo a una fuerte involución de los estándares de protección social a través de las reformas «anticrisis» ${ }^{32}$. Seguramente la doctrina jurisprudencial más paradigmática en este sentido se contiene en las SSTC $119 / 2014$ y $8 / 2015$, a propósito de los recursos presentados contra la Ley 3/2012, de 6 de julio, de Medidas Urgentes para la reforma del mercado laboral. La devaluación que se opera en esta norma de algunos derechos sociales «fundamentales» — como la negociación colectiva y el valor vinculante de los acuerdos — se infiere en primer lugar de la «relativización» que defiende el TC de la garantía de su contenido esencial. La tesis que defiende supone en realidad el vaciamiento del potencial prescriptivo que ha sido garantizado por el artículo 35.1, y por conexión la insustancialidad de otro derecho fundamental como el consagrado en el 28 (libertad sindical). El Tribunal va a renunciar directamente a su potestad para controlar la adecuación constitucional de aquellas opciones técnico- legislativas que realizan una interpretación reduccionista de estos derechos, desde el momento en que no se considera competente para fiscalizar «el margen de apreciación que corresponde al legislador democrático», o para «exa-

30 Las contribuciones doctrinales sobre la relación entre crisis económica, estabilidad presupuestaria y regresión de los derechos sociales son abundantes. Hemos aportado nuestro punto de vista sobre este tema en G. RuIZ-RICO, La constitución normativa y el principio de estabilidad presupuestaria. Istituzioni del federalismo: rivista di studi giuridici e politici, n. ${ }^{\circ} 1,2013$, pp. 229-263.

31 El Comité Europeo de Derechos Sociales (Consejo de Europa, Carta Social Europea) ha criticado duramente el insuficiente nivel que han alcanzado algunos derechos sociales básicos. Concretamente en un informe del 2014 el Comité detectaba, entre otras violaciones de la Carta por el Estado español, el incumplimiento de la obligación de «establecer o mantener un sistema de Seguridad Social» (art. 12.1), al considerar que sus prestaciones son, en muchos aspectos, «manifiestamente inadecuadas», en aspectos esenciales como la salud y el empleo. Sobre la idoneidad dogmática y jurídica de los derechos sociales en la esfera europea y convencional, vid. L. JimENA QUESADA, «La factibilidad de los derechos sociales en Europa: debate actual y perspectivas», en Estudios de Economía aplicada, vol. 27-3, 2009, pp. 743-766.

32 Esta interpretación regresiva de los derechos sociales ha sido tradicionalmente rechazada por un sector doctrinal. Como más representativos, L. López GUERRA, en «Las dimensiones del Estado social de Derecho», Sistema: Revista de ciencias sociales, 1980, núm. 38-39, pp. 171 y ss.; y L. PARejo Alfonso, «El Estado social y la Administración prestacional», en Revista Vasca de Administración Pública, núm. 57, 2000, pp. 17 y ss. 
minar la oportunidad de la medida legal para decidir si es la más adecuada o la mejor de las posibles». Resulta además muy indicativo de esta tesis autorestrictiva el hecho de que, en ninguno de sus fundamentos jurídicos, se haga referencia a estos derechos como «derechos fundamentales».

El método jurisprudencial de semantización constitucional consiste en convertir a la crisis económica — en palabras del TC, «el escenario económico de la crisis» o «el ajuste racional de las estructuras productivas a las sobrevenidas circunstancias del mercado»- en un auténtico y efectivo parámetro de constitucionalidad, a partir del cual es posible justificar la eliminación de los niveles mínimos de virtualidad normativa que encierra la noción del «contenido esencial» de los derechos fundamentales afectados. Este «doble juicio de constitucionalidad» —como lo denomina el voto particular de la STC 8/2015 - consolida una línea interpretativa que tiene manifestaciones también en otras resoluciones donde se resuelven conflictos de naturaleza competencial, generados por las iniciativas adoptadas por algunas CC.AA. para hacer frente en su ámbito territorial a algunos de los efectos más negativos desde el punto de vista social de la crisis económica. Sin ánimo de ser exhaustivos ahora podríamos traer a colación como casos más emblemáticos las sentencias en las que se rechazan la constitucionalidad de aquellas normas autonómicas que pretendían superar los déficits prestacionales en derechos como la vivienda, salud o medio ambiente ${ }^{33}$. Sin duda, el efecto colateral inmediato de esta jurisprudencia apunta a una lectura de la Constitución territorial en clave de «recentralización».

Pero de la reciente jurisprudencia constitucional en materia de derechos sociales interesa destacar asimismo una doctrina «progresiva» de signo opuesto que empieza abrirse paso, aunque todavía desde posiciones minoritarias en el Tribunal. Por su especial interés en este sentido merece la pena traer a colación la propuesta metodológica que plantea el voto particular de la STC 139/2016,

33 Como más representativos de esta doctrina jurisprudencial, anotamos la resoluciones donde el TC respalda y estima los recursos presentados por el Estado contra Ley catalana Ley 2/2014, que prohibía el fracking en Cataluña (STC 73/2016), contra el Decreto-ley 6/2013, de 9 de abril, de medidas para asegurar el cumplimiento de la Función Social de la Vivienda (Sentencia 93/2015). El Estado ha recurrido también algunos artículos de la ley catalana 24/2015, de medidas urgentes para afrontar la emergencia en el ámbito de la vivienda y la pobreza energética; concretamente medidas que se regulan allí como la segunda oportunidad para los hogares endeudados o la cesión obligatoria de pisos por los grandes tenedores de vivienda; asimismo ha impugnado preceptos de la Ley 14/2015, de Cataluña, del impuesto sobre las viviendas vacías. Recientemente se ha analizado el problema de la incidencia de la crisis y su repercusión en la esfera competencias «sociales» autonómicas (sanidad, vivienda, servicios sociales o pobreza energética» en J. Tornos MÁs, «Derechos sociales, Comunidades Autónomas y crisis económica», en Informe de las Comunidades Autónomas 2016, IDP, Barcelona, 2017, pp. 35-77. 
donde llega a construir una interpretación «alternativa» sobre la condición de estos derechos como efectivos potenciales parámetros en el control de constitucionalidad ${ }^{34}$. Aun cuando admite la reversibilidad en la determinación del contenido de un derecho social (salud), aspira a poner ciertos límites sustantivos a la libertad de configuración y desarrollo legislativos. La técnica consistiría en la aplicación de un triple test de control que debería superar en todo caso las medidas restrictivas o regresivas de un derecho social-prestacional. Primero, la obligación de que se adopten en normas con rango de ley; lo que implica una interpretación más «rigorista» o formalista de la referencia del artículo 53-3 (legislación positiva), y la equiparación en la práctica con los demás derechos constitucionales amparados por la garantías normativa del art.53-1 (sólo por ley). En segundo lugar, la propuesta de que las limitaciones de los derechos sociales deben ser «necesarias en una sociedad democrática»y, por último, deben responder adecuadamente al principio de proporcionalidad. Creemos que la tesis de que los anteriores criterios, de origen jurisprudencial, resultarían validos como paradigma de una nueva teoría constitucional que serviría para frenar la interpretación «absolutizadora», o «hegemónica» en todo caso, que se ha hecho hasta ahora del principio de estabilidad presupuestaria sobre el Estado social. Las condiciones que se han señalado podrían convertirse así en criterios de general aplicación a la hora de llevar a cabo el test de constitucionalidad de aquellas leyes que traten de imponer nuevos recortes en prestaciones ya reconocidas y sobre las que se había construido la cohesión social.

\section{EL DESARROLLO TERRITORIAL DE LA CONSTITUCIÓN SOCIAL}

La construcción de un modelo territorial caracterizado por un elevado grado de descentralización ha determinado sin duda un proceso de intensa centrifugación competencial en el ámbito de los principios y derechos sociales señalados

${ }^{34}$ La Sentencia en cuestión resuelve el recurso presentado contra el Real Decreto Ley 16/2012, sobre medidas urgentes para garantizar la sostenibilidad del Sistema Nacional de Salud. En una línea muy similar se pueden alinear votos particulares como los que se defienden en la STC 93/2015, sobre la Ley $1 / 2010$, de 8 de marzo, reguladora del derecho a la vivienda en Andalucía, y la disposición adicional segunda del Decreto-ley 6/2013, de 9 de abril, de medidas para asegurar el cumplimiento de la Función Social de la Vivienda, normativa en la que se contemplaban actuaciones como la suspensión del lanzamiento en situaciones de necesidad, la creación de un fondo de viviendas propiedad de entidades de crédito, o la expropiación temporal del uso de la vivienda. El TC declaró nulos algunos de sus preceptos amparándose en una interpretación bastante restrictiva de la competencia autonómica para incidir en el «contenido esencial del derecho a la propiedad privada de la vivienda». 
en la esfera constitucional ${ }^{35}$. En efecto, todo el sistema de atribuciones EstadoComunidades Autónomas (CCAA) diseñado por la norma fundamental, y luego complementado por los Estatutos de Autonomías (EEAA), ha venido a residenciar la garantía y satisfacción de los derechos sociales principalmente en el ámbito institucional autonómico. No obstante se reservan en favor del Estado aquellas potestades normativas que aseguran una uniformidad «básica» en su ejercicio; en definitiva, la territorialización de funciones y políticas públicas en materia social no ha podido ni puede llevar a la anulación de aquellos mecanismos diseñados para dotar de una necesaria homogeneidad normativa a los derechos constitucionales, a partir de la cual se garantice una igualdad esencial o mínima, desde el punto de vista territorial, en los estándares de la protección socio-asistencial.

Efectivamente, el régimen distributivo de competencias que se infiere del texto fundamental y los diferentes Estatutos otorga un indiscutible protagonismo a las instituciones autonómicas en el desarrollo del programa social constitucionalizado. Sin embargo, se ha podido constatar en las primeras décadas de funcionamiento de este modelo la preferencia por una interpretación extensiva de los denominados títulos competenciales «horizontales» del Estado: igualdad básica en el ejercicio de los derechos constitucionales (art. 149.1.1) y bases y coordinación de la planificación general de la actividad económica (149.1.13); en esta misma dirección apuntaría la obligación de regular algunos de los derechos sociales más emblemáticos (educación, libertad sindical) a través de una ley orgánica estatal.

Con las anteriores premisas de orden constitucional el sistema se ha inclinado frecuentemente — aunque la tendencia «pendular» es igualmente sintomática (García Morillo) — hacia una concepción centrípeta en la aplicación legislativa y jurisprudencial de las cláusulas de naturaleza social. Su efecto principal y directo ha sido la consolidación de unos niveles notables de uniformización normativa en la mayor parte de los derechos constitucionales que se enmarcan dentro de la órbita del Estado social. Para el principio del autogobierno territorial esto ha significado una evidente restricción de sus potencialidades competenciales; pero desde una óptica sustantiva esta dialéctica ha significado al mismo tiempo la posibilidad de marcar unas condiciones mínimas, o básicas, en los estándares de protección social que deben quedar garantizados en todo el Estado y para el conjunto de la ciudadanía.

35 Vid. una de las referencia doctrinales más destacables, J. J. SolOZÁBAL. «El Estado social como Estado Autonómico», en Teoría y Realidad Constitucional, n. ${ }^{\circ}$ 3, 1999. 
En todo caso, no es posible cuestionar que hoy las CCAA cuentan con suficiente cobertura constitucional y estatutaria para disponer de su propia programación social, y en consecuencia también, para imprimir el ritmo que consideren más adecuado al cumplimiento de las directrices social-prestacionales indicadas en ambas esferas normativas ${ }^{36}$. Las fórmulas de habilitación son diversas y aparecen contempladas con bastante nitidez en la última generación de EEAA. Cabe afirmar por tanto que quedan espacios regulativos suficientes a disposición de las CC.AA. para cumplir con los mandamientos estatutarios que imponen garantías efectivas de los diferentes derechos sociales estatutarios ${ }^{37}$. Más aún cuando en los últimos Estatutos se ha llevado a cabo una auténtica ampliación «dogmática», con la incorporación de verdaderas Declaraciones de derechos, la mayoría de naturaleza social, con los cuales se otorga una legitimación preferencial a la intervención de las CC.AA., en la realización de los mandatos que aquéllos incorporan para los poderes públicos autonómicos. No obstante, esta amplificación y superior precisión que se observa en los nuevos catálogos de derechos y principios sociales «estatutarios» no ha llegado a superar las dificultades y debilidad normativa que sufren sus homólogos en la esfera constitucional.

Visto de desde otro ángulo, una de las consecuencias principales para las CC.AA. de la inclusión de estas declaraciones de derechos ha sido —o debería ser- la inapelable auto-restricción de su respectiva autonomía o poder de autogobierno ${ }^{38}$; como mandatos de optimización marcan unas directrices de obligado cumplimiento, con las que se circunscribe en un sentido finalista el principio del pluralismo político. En efecto, la vinculación de aquel «programa social estatutario» con el principio dispositivo y el autogobierno ${ }^{39}$ no puede explicarse solamente en clave competencial, ya que determina sin duda un indirizzo politico, que se impone sobre el principio democrático en la toma de decisiones de los poderes públicos autonómicos ${ }^{40}$.

36 Vid. A. Porras Nadales, «Estado social y Estado Autonómico». En «Estudios de Derecho Público». Homenaje a Juan José Ruiz-Rico. Madrid. 1997. Tecnos. Madrid. 1997.

37 Vid. R. Canosa Usera, «La declaración de derechos en los nuevos Estatutos de Autonomía», en Teoría y realidad constitucional, núm. 20, 2007, pp. 59-115.

${ }^{38}$ En este sentido se pronunciaba ya el Consejo Consultivo de la Generalidad en su Dictamen 269 (1 de Septiembre del 2005).

39 Hemos defendido que estas cláusulas estatutarias de contenido social podrían ofrecer una especie de implícito «plus funcional» en favor de las CC.AA., con el que sería legítimo interpretar en un cierto sentido restrictivo las competencias estatales de carácter compartido que inciden directa o tangencialmente en estos mismos ámbitos materiales. Vid. G. Ruiz-Rico Ruiz, «Los derechos sociales en el Estado constitucional». Edit. Porrúa, México, 2016, p. 346.

40 Defiende también la compatibilidad constitucional de esas limitaciones G. PisArello, en «Los derechos sociales y sus garantías», Ed. Trotta, Madrid, 2007. En esa misma línea nos hemos 
Desde el punto de vista sustantivo, los Estatutos han dividido esa dimensión dogmática» en dos categorías normativas: derechos (potencialmente subjetivos) de un lado, y principios sociales y económicos de carácter programático; proporcionando además a cada uno de estos grupos diferentes instrumentos de garantía. Resulta obvio que todos requieren la «mediación» del legislador primero y la implementación administrativa en segundo lugar. Sin embargo, en ocasiones su aplicabilidad directa puede derivar de la propia norma estatutaria; sucede en concreto cuando aquélla enuncia de forma explícita derechos de contenido muy concreto y definido, lo que facilita una posible posición jurídica prestacional (Gomes Canotilho) en favor del ciudadano, desde la cual no resultaría del todo imposible la utilización de instrumentos jurisdiccionales para garantizar su ejercicio de forma individualizada ${ }^{41}$.

Sin duda, la contribución más significativa de los nuevos Estatutos ha sido la articulación de un sistema de tutela específico para los derechos y principios rectores «autonómicos». Especialmente novedoso resulta el modelo de garantía implantado en los Estatutos de Cataluña (2006) y de Andalucía (2007). No obstante, esta pretensión del «estatuyente» todavía no se ha concretado lo suficiente; en buena medida porque para llevarse a término se requerirá siempre - sobre todo en lo que se refiere a garantías de orden jurisdiccional — la colaboración del legislador estatal.

El análisis de los mecanismos de tutela estatutorizados debe partir de nuevo de la división interna que se observa dentro de estos Estatutos entre «principios rectores» y «derechos». Respecto de los primeros, el Estatuto catalán del 2006 (EAC) señala el carácter «informativo» de los programas y fines sociales, de manera muy semejante a cómo se había previsto en el artículo 53.3 de la CE. Pero al mismo tiempo va a intentar superar la tradicional debilidad normativa de este tipo de cláusulas sociales, incorporando simultáneamente una serie obligaciones estatutarias bastante explícitas que pretenden condicionar los márgenes de discrecionalidad en su desarrollo normativo por las instituciones autonómi-

pronunciado en otro lugar; y G. RuIz-RICO, «El derecho constitucional a la vivienda. Un enfoque sustantivo y competencial», Ministerio de Vivienda, Madrid, 2008. En la posición contraria se alinea L. M. ${ }^{a}$ DíEz-Picazo, en «¿Pueden los Estatutos de Autonomía declarar derechos, deberes y principios?, Revista Española de Derecho Constitucional, núm. 78, 2006.

${ }^{41}$ Un ejemplo de lo que estamos subrayando sería, dentro del Estatuto de Autonomía de Andalucía del 2007, el derecho a la gratuidad de los libros de texto en la enseñanza obligatoria dentro de los centros públicos (art. 21-5. ${ }^{\circ}$ ), o bien el derecho a una segunda opinión médica (art. 22-2. ${ }^{\circ}$-h), otorgados con una potencialidad subjetiva evidente. 
cas $^{42}$. La vocación garantista que se infiere del articulado del EAC se pone en evidencia finalmente al proponer una fórmula claramente distinta - y opuesta incluso- a la que establece la CE (art. 53.3) para esta categoría de principios sociales programáticos, al reconocer explícitamente su capacidad para hacerse valer en la esfera jurisdiccional ("Los principios rectores son exigibles ante la jurisdicción, de acuerdo con lo que determinan las leyes y las demás disposiciones que los desarrollan»).

En el caso del Estatuto andaluz del 2007 (EAA), además de reiterar las posibilidades de invocación o alegabilidad ante los órganos judiciales, se añaden algunos mecanismos con los cuales se suministran variables que condicionan la autonomía de legislador y refuerzan la potencial virtualidad normativa de los mandatos sociales estatutarios: «una legislación pertinente», "la garantía de una financiación suficiente» $\mathrm{y}$ "la eficacia y eficiencia de las actuaciones administrativas» (art. 40.2 EAA). Es evidente que sobre la base de estas directrices metodológicas la norma estatutaria andaluza está imponiendo unas condiciones en las cuales se debe producir el despliegue normativo y el diseño de las políticas públicas sociales.

En lo que se refiere a los «derechos estatutarios», la principal novedad que introduce el EAC radica en el paralelismo con los instrumentos de tutela previstos en la $\mathrm{CE}$, de los que disfrutan únicamente los denominados como «derechos fundamentales». En primer lugar, un carácter vinculante que se proyecta tanto para los poderes públicos autonómicos como, en la medida en que lo permita su naturaleza jurídica, a las relaciones entre particulares (art. 37.1. ${ }^{\circ}$ ). Se añade asimismo una «reserva de ley», que se despliega en una doble dirección: la aprobación de una «Carta de los derechos y los deberes de los ciudadanos de Cataluña» y el establecimiento necesariamente por ley de la «regulación esencial y el desarrollo directo» de estos derechos (art. 37.2. ${ }^{\circ}$ y 3. ${ }^{\circ}$ ). Por último, el sistema se completa con la previsión de un mecanismo o doble vía de «control de estatutoriedad». La primera se activa ante el Consejo de Garantías Estatutarias y tiene como objeto los proyectos normativos con rango de ley (reformas estatutarias, proyectos y proposiciones de leyes, proyectos de Decretos Legislativos) ${ }^{43}$. La segunda tiene carácter

42 Los poderes públicos catalanes resultan así destinatarios de obligaciones más definidas, como serían la de "orientar las políticas públicas de acuerdo con los principios rectores que establecen la Constitución y el presente Estatuto», y de forma más concreta la de "promover y adoptar las medidas necesarias para garantizar su plena eficacia» (art. 39).

43 Esta vía ante el Consejo de Garantías Estatutarias fue objeto de regulación normativa en la ley 2/2009 aprobada por el Parlamento catalán, en donde se estableció un verdadero mecanismo de control previo de estatutoriedad. La eficacia de este instrumento de fiscalización estatutaria quedaba garantizada, desde el momento en que el dictamen del Consejo de Garantías tenía un 
jurisdiccional, y se activaría ante el Tribunal Superior de Justicia de Cataluña, de acuerdo con el procedimiento que en su momento establezca la LOPJ ${ }^{44}$.

Por su parte, el EAA incorpora unas fórmulas prácticamente idénticas a las del Estatuto catalán, si bien parece querer reforzar la aplicabilidad «legislativa» de los derechos estatutarios, al imponer al legislador una obligación muy definida en orden a concretar en las leyes que los desarrollen «las prestaciones y servicios vinculados, en su caso, a esos derechos».

En definitiva, la principal conclusión que se extrae del examen de las cláusulas de garantías diseñadas — al menos en los Estatutos catalán y andaluz- para esta generación de derechos estatutarios sociales sería la voluntad de implantar un inédito control de estatutoriedad, como expresión indirecta de una concepción virtualmente constitucional que se quiso proporcionar por primera vez a los EE.AA. La fundamentación en la que se apoyarían los anteriores instrumentos y fórmulas de tutela no es otra que la voluntad de implantar un «contenido estatutario» de los derechos sociales, sobre el cual no existiría una absoluta disponibilidad o autonomía regulativas, y cuya vulneración puede en teoría proporcionar una base, de naturaleza esencialmente «supralegal», para ser invocada en la esfera jurisdiccional.

Pero la anterior conclusión, aun cuando pueda resultar lógica desde una interpretación literal de los preceptos estatutarios, no ha encontrado apoyo suficiente en la jurisprudencia constitucional. Más bien al contrario, choca en gran medida con la doctrina que emana de las resoluciones en las que el TC ha tenido que pronunciarse sobre los límites constitucionales de los nuevos EEAA. En efecto, la STC $247 / 2007^{45}$ suministraba ya los indicadores más claros para conocer el valor normativo y eficacia jurídica de los derechos sociales estatuarios ${ }^{46}$.

carácter vinculante para el Parlamento autonómico. Lo establecido así en el Estatuto (art 76.4. ${ }^{\circ}$ ), se detallaba después por la Ley 2/2009: «La tramitación de un texto que hay a sido objeto de un dictamen vinculante del Consejo de Garantías Estatutarias no puede proseguir si no se suprimen o modifican los preceptos o partes de precepto a que se refiere el apartado 2 (los declarados contrarios al Estatuto) (art. 18.3.'). Sin embargo el TC rechazaría después ese carácter vinculante del juicio u opinión del Consejo en la Sentencia sobre el EAC (STC 31/210). Vid. Marc Carrillo y Roberto Romboli, Los Consejos de garantías estatutarias. Fundación Coloquio Jurídico Europeo. Madrid. 2009.

${ }_{44}$ Entre los trabajos doctrinales que pueden ser consultados en relación con este tema, vid. M. Barceló y J. Vintrò. Derecho Público de Cataluña. Atelier. Barcelona. 2008. También ApaRicio Pérez, M. A y Barceló, M. «Los derechos públicos estatutarios», en Derechos y Principios Rectores en los Estatutos de Autonomía (Aparicio Pérez. M. A. Edit.), Atelier, Barcelona, 2008.

${ }^{45}$ Sentencia del TC que resuelve el recurso de inconstitucionalidad presentado por la Comunidad Autónoma de Aragón contra el nuevo Estatuto de Autonomía valenciano (Ley Orgánica 1/2006, de 10 de abril).

${ }^{46}$ La Sentencia resuelve por otro lado la incertidumbre que se había planteado en torno a la capacidad de las CC.AA. para incluir en sus estatutos catálogos de derechos, en base a una interpretación flexible del artículo 147 (CE), a lo que no se opone el TC al considerar que ese precepto 
Sin duda una de las principales aportaciones de la Sentencia 247/2007 se refiere a la cuestión de la potencial eficacia de los derechos estatutarios. El Tribunal establece aquí una división bastante original —aunque no por ello menos discutible - al diferenciar entre derechos que tendrían su anclaje constitucional en el artículo 147-2. ${ }^{\circ}$-c (organización de las instituciones autónomas propias) y aquellos otros que se reconocen en virtud de «las competencias asumidas dentro del marco de la Constitución» (147-2. $\left.{ }^{\circ}-\mathrm{d}\right)$. A partir de esta línea de demarcación, el TC va a otorgar una calidad normativa desigual a los derechos derivados, respectivamente, del principio democrático y los derechos de naturaleza social. La tesis esencial que defiende en este punto el TC es que los primeros sí pueden tener el carácter de «derechos públicos subjetivos», y disfrutar por consiguiente de eficacia directa e inmediata. Por el contrario, la mayoría de los derechos reconocidos en el Estatuto, relacionados con los espacios competenciales atribuidos por éste y configurados como derechos de naturaleza social, no tendrían ese carácter y, por tanto también, no podrían en ningún caso ser alegados en la esfera jurisdiccional.

Resulta fácil descubrir en esta argumentación un concepto bastante restrictivo y «estatalista» de la noción «derecho público subjetivo», en virtud del cual solo la CE podría generar este tipo de derechos, salvo las contadas excepciones relacionadas con la dimensión «democrática» de la autonomía territorial ${ }^{47}$. No obstante, tras la afirmación general que rechaza la posibilidad de conferir un nivel mínimo de eficacia jurídica basada en la inmediatez y aplicabilidad directa de los derechos estatutarios, el TC viene a aceptar al menos su carácter «vinculante», si bien desde su condición de mandatos o directrices obligatorias para los poderes públicos autonómicos ${ }^{48}$. Por tanto, la sentencia estaría admitiendo

constitucional solo impone y garantizaría un objeto «mínimo», ya que —en su opinión—los Estatutos de Autonomía pueden incluir con normalidad en su contenido, no solo las determinaciones expresamente previstas en el texto constitucional a que hemos aludido, sino también otras cuestiones, derivadas de las previsiones del artículo $147 \mathrm{CE}$ relativas a las funciones de los poderes e instituciones autonómicos, tanto en su dimensión material como organizativa, y a las relaciones de dichos poderes e instituciones con los restantes poderes públicos estatales y autonómicos, de un lado, y, con los ciudadanos, de otro».

${ }^{47}$ La posibilidad de que los EE.AA. puedan generar «derechos públicos subjetivos» queda circunscrita a un ámbito limitado, sobre el que ya había tenido oportunidad de pronunciarse el TC: STC 36/1981, (derechos de inviolabilidad e inmunidad de los parlamentarios autonómicos), STC 82/1986 (derechos lingüísticos), STC 4/1992 (designación de Senadores por las Comunidades Autónomas) o STC 225/1998 (sistema de representación proporcional de las Asambleas legislativas de las Comunidades Autónomas).

${ }^{48}$ La posición del TC se expresa con bastante claridad en los siguientes razonamientos: «Partiendo de este dato, nada impide que el Estatuto de Autonomía, en cuanto norma institucional básica de la Comunidad Autónoma, al atribuir las competencias que han de ejercer los poderes públicos autonómicos, les impongan, de modo directo, criterios o directrices para su ejercicio o que lo hagan, de modo indirecto, mediante la formalización de enunciados o declaraciones de derechos a favor de los particulares. Se trata, en ambos 
un cierto nivel de normatividad real y efectiva, compatible con un sistema de control de «estatutoriedad» que se pueda articular y poner en funcionamiento, siempre dentro del marco de las competencias de autoorganización de las CCAA y respetando las que en materia de potestad jurisdiccional corresponden al Estado central.

En consecuencia, y a pesar de las apariencias tan negativas que presenta, pensamos que la Sentencia 247/2007 no neutraliza del todo la eficacia de los derechos estatutarios, al afirmar de forma concluyente y clara su carácter «prescriptivo» para los poderes autonómicos. Se trataría, en efecto, de una vinculación «debilitada» o «mediatizada», ya que para su cumplimiento requiere de una configuración legislativa autonómica que desarrolle las previsiones estatutarias. Pero en realidad este condicionamiento afecta también a la mayor parte de los denominados derechos fundamentales, sin que por ello se cuestione su carácter como derechos justiciables.

\section{CONCLUSIONES: EL ESTADO SOCIAL EN UNA FUTURA CONSTITUTIONE FERENDA}

El balance de estos cuarenta años de vigencia de la CE de 1978 en lo que se refiere al desarrollo, normativo y jurisprudencial, del concepto social de Estado refleja una evidente incongruencia entre la escasa dosis de normatividad con la que fueron concebidos constitucionalmente la mayoría de los derechos y principios sociales, y la expansión jurídica e institucional que estos mismos han alcanzado durante este período de tiempo ${ }^{49}$. Al adoptar esta segunda perspectiva metodológica, se puede reconocer fácilmente cómo en la esfera del derecho legislativo y la organización administrativa aquellos fines y compromisos constitucionalizados han adquirido una auténtica fundamentalidad social y política.

Este contraste entre la formulación positiva y la realidad constitucional de su despliegue jurídico y administrativo conduce necesaria e inevitablemente - a nuestro juicio - a replantear la conservación del marco y sistema de garantías vigente en la norma fundamental de una parte significativa de las actuales cláusulas sociales.

casos, de mandatos al legislador y restantes poderes públicos autonómicos, imponiéndoles prescripciones que son vinculantes para los mismos con independencia de la veste de que se revistan».

49 Coincidimos por tanto con el balance conclusivo que hace TEROL BECERRA, referido en ese caso a las tres primeras décadas de vigencia de la CE. Vid. M. Terol BeCErra, «Treinta años de desarrollo constitucional y legislativo de los derechos sociales: derechos ciudadanos y principios rectores», en «Derechos sociales y Principios Rectores», Tirant lo Blanch, Valencia, 2012, p. 85. 
Por otra parte, sería asimismo conveniente aprovechar esa hipotética operación para proceder a un necesario aggiornamento del Título Primero, en la línea de lo que ya se ha llevado a cabo por la última generación de Estatutos de Autonomía ${ }^{50}$. No solo por una simple cuestión de distancia cronológica, sino sustancialmente por las profundas transformaciones culturales, sociales y económicas que se han producido desde entonces, buena parte de las cuales se han ido consolidado de manera progresiva en el ordenamiento infraconstitucional. Si la legislación ordinaria ya ha consolidado las prioridades de la acción social de los poderes públicos que «conectan» con las nuevas demandas de la sociedad, se trata ahora de darles la forma adecuada en una dimensión constitucional, bien como «nuevas» figuras o categorías derechos sociales, bien como nuevas dimensiones materiales o sustantivas de los que ya forman parte de la vigente Declaración de derechos.

Por último, sería necesario complementar esa eventual amplificación constitucional del Estado social con la superación de una dicotomía entre derechos fundamentales y no fundamentales. Es una frontera marcada por la propia CE, que puede tener efectos inocuos en el plano doctrinal, pero que impacta sin duda sobre las opciones de tutela que tienen —o padecen en este caso- la mayoría de los derechos sociales. En una hipótesis «recreativa» del sistema de garantías constitucionales, cabría proponer dos alternativas, a la búsqueda una vez más de una lógica coherencia con el desarrollo normativo y potencial sociopolítico que han adquirido en la actualidad. De un lado, y hay que referirse de nuevo a esas disposiciones que forman parte del bloque de constitucionalidad (EEAA), eliminando - total o parcialmente- esa línea divisoria que en el texto fundamental separa de manera radical, desde el punto de vista de su naturaleza teórica y de los instrumentos de tutela, a los derechos civiles y políticos de los derechos sociales. O bien, como segunda opción, para intentar implantar unos mecanismos de tutela (normativos y jurisdiccionales) específicamente diseñados atendiendo a su condición «directiva» o prestacional ${ }^{51}$.

50 Entre esos nuevos derechos estatutarios e inéditos contenidos de los derechos sociales —ya constitucionalizados - cabría mencionar, entre otros, algunos perfiles derivados del principio de igualdad real y efectiva (derecho a la orientación sexual, a la protección frente a violencia de género, igualdad de trato para modelos familiares y matrimoniales no tradicionales), nuevos «derechos sociales sustantivos» (derecho a percibir una renta básica, acceso a las nuevas tecnologías), derechos de proyección institucional (derecho a promover consultas populares, derecho a una buena administración), derechos ligados a la dignidad y la personalidad (derecho a una muerte digna), y algunos derechos «metodológicos» o instrumentales, dotados de un mayor grado de inmediatez y exigibilidad (gratuidad de los libros de texto, cuidados paliativos o segunda opinión médica).

51 Tenemos que recordar en este punto la capacidad de ingeniería «constitucional» que han puesto de manifiesto los poderes estatuyentes de algunas CC.AA. (Cataluña, Andalucía). En primer 
Title:

The territorial development of the Social Constitution.

\title{
Summary:
}

1. Deficits and normative potentialities of social rights in the Spanish Constitution of 1978. 2. An approximation to the faltering constitutional jurisprudence on social rights and their relative normative capacity. 3. Budgetary stability and economic crisis: new canons of constitutionality of social rights in legislation and constitutional jurisprudence. 4. The territorial development of the Social Constitution. 5. Conclusions: the Social state in a future Constitutione ferenda.

\section{Resumen:}

La Constitución Española de 1978 reconoce un amplio catálogo de derechos sociales, pero no ha previsto instrumentos eficaces para su tutela jurídica. Los derechos sociales constitucionalizados se configuran ante todo en forma de principios y mandatos dirigidos a los poderes públicos, con escasas posibilidades de ser utilizados en el control de constitucionalidad de las normas. La crisis económica y la constitucionalización del principio de estabilidad presupuestaria han venido a debilitar más aún su potencialidad normativa. La implantación del Estado Autonómico ha tenido como resultado una elevada dosis de descentralización en materia de derechos sociales. Se hace necesaria una reforma constitucional que permita reforzar la eficacia de los derechos del Estado social.

\begin{abstract}
:
The Spanish Constitution of 1978 recognizes a wide catalog of social rights, but has not provided effective instruments for its legal protection. Constitutionalised social rights are shaped above all in the form of principles and mandates directed to public authorities, with
\end{abstract}

\footnotetext{
lugar, al superar aquella frontera marcada en el Título Primero de la CE, desde la cual se ha legitimado una constante devaluación normativa de los derechos sociales, constitucionalizados como «principios rectores» dentro de su capítulo tercero de este título. Pero en segundo término, los nuevos Estatutos han previsto unos dispositivos de garantía de esos - formalmente ya - «derechos» sociales que suponen, de un lado, la adaptación al plano autonómico de los mecanismos atribuidos por la CE solo a los «derechos fundamentales» (carácter vinculante, contenido «estatutario»), y de otro, la generación de nuevas fórmulas de protección normativa y jurisdiccional (obligación del legislador de incluir en las leyes los servicios y prestaciones concretas, y el derecho a los recursos judiciales frente a actos que los vulneres).
} 
little possibility of being used in the control of the constitutionality of norms. The economic crisis and the constitutionalisation of the principle of budgetary stability have further weakened its normative potentiality. The implementation of the Autonomous State has resulted in a high dose of decentralization in terms of social rights. A constitutional reform is necessary to strengthen the effectiveness of the rights of the Welfare state.

Palabras clave:

Constitución, derechos sociales, crisis económica, modelo territorial

Key words:

Constitution, social rights, economic crisis, territorial model. 